\title{
Novel Pathways in the Pathobiology of Human Abdominal Aortic Aneurysms
}

\author{
Irene Hinterseher ${ }^{a, b}$ Robert Erdman ${ }^{b}$ James R. Elmore ${ }^{c}$ Elizabeth Stahl ${ }^{b}$ \\ Matthew C. Pahl ${ }^{\mathrm{b}}$ Kimberly Derr ${ }^{\mathrm{b}}$ Alicia Golden ${ }^{\mathrm{b}}$ John H. Lillvis ${ }^{\mathrm{d}}$ \\ Matthew C. Cindric ${ }^{c}$ Kathryn Jackson ${ }^{b}$ William D. Bowen ${ }^{c}$ Charles M. Schworer $^{b}$ \\ Michael A. Chernousov ${ }^{b}$ David P. Franklin ${ }^{c}$ John L. Gray ${ }^{c}$ Robert P. Garvin ${ }^{c}$ \\ Zoran Gatalica ${ }^{\mathrm{e}}$ David J. Carey ${ }^{\mathrm{b}}$ Gerard Tromp $^{\mathrm{b}}$ Helena Kuivaniemi ${ }^{\mathrm{b}}$ \\ ${ }^{a}$ Department of Visceral, Thoracic and Vascular Surgery, Technical University of Dresden, Dresden, Germany; ${ }^{\text {b Sigfried }}$ \\ and Janet Weis Center for Research, Geisinger Clinic and 'Department of Vascular and Endovascular Surgery, Geisinger \\ Clinic, Danville, Pa., ' Center for Molecular Medicine and Genetics, Wayne State University School of Medicine, Detroit,

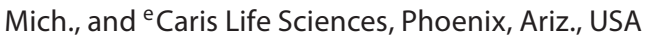

\section{Key Words}

Gene expression • Vascular biology $\cdot$ Aorta $\cdot$ Abdominal aortic aneurysm

\begin{abstract}
Objectives: Abdominal aortic aneurysm (AAA), a dilatation of the infrarenal aorta, typically affects males $>65$ years. The pathobiological mechanisms of human AAA are poorly understood. The goal of this study was to identify novel pathways involved in the development of AAAs. Methods: A custom-designed 'AAA-chip' was used to assay 43 of the differentially expressed genes identified in a previously published microarray study between AAA $(n=15)$ and control $(n=15)$ infrarenal abdominal aorta. Protein analyses were performed on selected genes. Results: Altogether 38 of the 43 genes on the 'AAA-chip' showed significantly different expression. Novel validated genes in AAA pathobiology included ADCY7, ARL4C, BLNK, FOSB, GATM, LYZ, MFGE8, PRUNE2, PTPRC, SMTN, TMODI and TPM2. These genes represent a wide range of biological functions, such as calcium signal-
\end{abstract}

ing, development and differentiation, as well as cell adhesion not previously implicated in AAA pathobiology. Protein analyses for GATM, CD4, CXCR4, BLNK, PLEK, LYZ, FOSB, DUSP6, ITGA5 and PTPRC confirmed the mRNA findings. Conclusion: The results provide new directions for future research into AAA pathogenesis to study the role of novel genes confirmed here. New treatments and diagnostic tools for AAA could potentially be identified by studying these novel pathways.

Copyright $\odot 2012$ S. Karger AG, Basel

\section{Introduction}

Abdominal aortic aneurysm (AAA) is a complex disease of the aging population [1]. Rupture of AAA is associated with a high mortality rate, making aortic aneurysms a leading cause of death [2]. Although multiple

I.H. and R.E. contributed equally to the work.

\section{KARGER}

Fax +4161306 1234

E-Mail karger@karger.ch

www.karger.com
(C) 2012 S. Karger AG, Basel

$1015-2008 / 13 / 0801-0001 \$ 38.00 / 0$

Accessible online at:

www.karger.com/pat
Helena Kuivaniemi, MD, $\mathrm{PhD}$

Sigfrid and Janet Weis Center for Research, Geisinger Clinic

100 North Academy Avenue

Danville, PA 17822-2610 (USA)

Tel. +1 570271 5593, E-Mail shkuivaniemi@geisinger.edu 
characteristics of AAA pathogenesis including inflammation, autoimmunity, vascular smooth muscle cell (VSMC) apoptosis, oxidative stress, and extracellular matrix (ECM) degradation are known, the details on the pathobiology remain unclear [3].

A genomewide expression analysis provides an unbiased approach to study disease pathogenesis at the molecular level. Three microarray studies have been performed with samples obtained from human AAA patients. One of the studies compared AAA tissues to age- and sex-matched control aortic tissues taken from infrarenal aorta and identified over 3,000 genes with significantly elevated or decreased expression levels in AAA tissue compared to control aortic tissue [4]. Another microarray-based expression study investigated the differences between the rupture site of AAA and the intact wall area in the same patients [5]. One expression study of peripheral blood has also been performed for AAA patients to study different stages of the AAA development [6].

In the current study, we used the results of a previously published microarray study [4] to confirm differentially expressed genes using a custom array, 'the AAAchip', with 43 differentially expressed genes. The goal was to identify novel genes not previously implicated in AAA pathobiology. Follow-up studies included protein analyses with Western blots and immunohistochemical staining of human aortic tissue samples.

\section{Methods}

\section{Human Samples}

Aortic wall specimens were collected from patients undergoing AAA repair operations $(n=31)$ at the Geisinger Medical Center, Danville, Pa., USA, or at the Harper University Hospital, Detroit, Mich., USA. Nonaneurysmal aortic samples $(n=29)$ were collected from the infrarenal segment of aorta at autopsies or were obtained from National Disease Research Interchange (NDRI, Philadelphia, Pa., USA). Donor information is listed in online supplementary material, table S1 (for all online suppl. material, see www.karger.com/doi/10.1159/000339303). The collection of human tissues was approved by the Institutional Review Boards of Geisinger Clinic, Danville, Pa., USA, and Wayne State University, Detroit, Mich., USA. The investigation conformed to the principles outlined in the Declaration of Helsinki.

\section{RNA Isolation}

RNA for a new microarray study was extracted from 4 AAA and 4 control infrarenal abdominal aortic samples using TRIZOL RNA Isolation Protocol (Invitrogen Corporation, Carlsbad, Calif., USA).
RNA for real-time quantitative RT-PCR (AAA-chip) of 15 independent AAA and 15 control samples (online suppl., table S1) was isolated with mirVana ${ }^{\mathrm{TM}}$ miRNA Isolation Kit (Ambion Applied Biosystems, Austin, Tex., USA). Quality of RNA samples was assessed by 2100 Bioanalyzer (Agilent Technologies, Inc., Santa Clara, Calif., USA).

Microarray Analysis and Design of a Custom PCR Array for Quantitative RT-PCR

There is only one published microarray-based expression study comparing human AAA tissues to nonaneurysmal infrarenal abdominal aortas from age- and sex-matched controls [4]. To provide additional evidence for selecting novel, differentially expressed genes for further studies, we carried out a new microarray-based expression analysis. Labelled cRNA of 4 AAA cases and 4 control aortic samples was prepared and hybridized to Affymetrix HGU133A chip according to the manufacturer's protocols (Affymetrix, Santa Clara, Calif., USA). Quality control procedures included examination of raw and adjusted intensity histograms and principal component analysis (PCA) for systematic bias. The probe set identified in the PCA was then analyzed $(R$ and Bioconductor) $[7,8]$ to find the probes with significant expression differences (False Discovery Rate, FDR < 0.05).

A custom PCR Array was designed with 43 genes of interest selected from our two microarray studies [4], (online suppl. table S2) and run on RNA samples isolated from a set of 15 human AAA samples and 15 control abdominal aorta samples (online suppl. table S1). The assays were run according to manufacturer's instructions (SA Biosciences-Qiagen, Frederick, Md., USA) in a 7,500 Fast Real Time PCR system (Applied Biosystems, Carlsbad, Calif., USA). Two housekeeping genes (GAPDH and RPL13A) were measured to standardize the results. The $\mathrm{p}$ values were calculated with the Wilcoxon rank-sum test using the Program R [8].

The biological functions of the differentially expressed genes were characterized by Gene Ontology (GO) and KEGG pathway analysis as described previously [4]. A network analysis was carried out with Ingenuity Pathways Analysis software version 9.0 (IPA, Ingenuity ${ }^{\circledR}$ Systems, Mountain View, Calif., USA, www.ingenuity.com).

Throughout the study we use gene symbols available from the National Center for Biotechnology Information (NCBI; http:// www.ncbi.nlm.nih.gov/).

\section{Preparation of Protein Lysates and Western Blots}

Aortic tissues were homogenized with a buffer containing 50 mM Tris, $\mathrm{pH}$ 8.0, $100 \mathrm{~mm} \mathrm{NaCl}, 5$ mM EDTA, 5 mM EGTA, 1\% Triton, $0.1 \%$ SDS, and a Roche mini-Complete Protease Inhibitor tablet/10 $\mathrm{ml}$ and Phosphatase Inhibitor Cocktail II (Sigma-Aldrich, St. Louis, Mo., USA). The samples were run on 4-15\% gradient polyacrylamide gels (Bio-Rad Laboratories, Hercules, Calif., USA). Proteins were transferred to PVDF membranes in a buffer containing 0.19 M glycine and $25 \mathrm{mM}$ Tris (Mini Trans-Blot Cell; Bio-Rad Laboratories). After blocking with $5 \%$ skim milk in $0.1 \mathrm{M}$ Tris, $\mathrm{pH} 7.5,0.154 \mathrm{M} \mathrm{NaCl}$, with $0.1 \%$ Tween 20 , the blots were incubated overnight at $4{ }^{\circ} \mathrm{C}$ with a primary antibody (online suppl. table S3). Blots were washed and incubated for one hour at room temperature with horseradish peroxidase-conjugated AffiniPure secondary antibody (Jackson ImmunoResearch Lab. Inc., West Grove, Pa., USA). Blots were washed and visualized using SuperSignalS West Pico Chemiluminescent Substrate (Thermo Scien- 
Table 1. Functional groups of the 43 differentially expressed genes selected for further study

\begin{tabular}{|c|c|c|}
\hline Biological function* & \multicolumn{2}{|l|}{ mRNA expression in AAA versus controls } \\
\hline $\begin{array}{l}\text { Cell development and } \\
\text { differentiation }\end{array}$ & $G A T M^{1}, G P R 65, P L E K^{1}, P T P R C^{1}$ & $\begin{array}{l}\text { CSRP2, HSPB2, LDOC1, NTRK3, PRUNE2, } \\
\text { SMARCD3, SMTN, ZBTB16 }\end{array}$ \\
\hline Inflammatory response & $\begin{array}{l}B L N K^{1}, C C L 4, C C L 8, C D 4^{1}, C D 48, C D 83, C X C R 4^{1}, F C G R 2 B \text {, } \\
\text { GPR65, LCP2, LYZ1 }, M X 2, N C F 4, P T P R C^{1}\end{array}$ & \\
\hline Other & ARL4C, DUSP6 ${ }^{1}, F^{\prime} O S B^{1}, I L 10 R A$, SAMSN1 & $\begin{array}{l}\text { LARP6, LMOD1, PDE8B, RAMP1, RASL12, } \\
\text { TMOD1, TPM2 }\end{array}$ \\
\hline
\end{tabular}

* Biological function was based on GO categories [14]. ${ }^{1}$ Molecules chosen for follow-up immunohistochemical analyses.

tific, Rockford, Ill., USA, Product\# 34080) according to manufacturer's instructions. Images were obtained using Lumi-Imager system, and quantified using LuminAnalyst 3.0 software (Boehringer Mannheim, Germany). Band intensities were adjusted for $\beta$-actin (ACTB) protein levels.

Human aortic SMCs (HASMC catalog \# 6110 from ScienCell Research Laboratories, Carlsbad, Calif., USA) and a macrophage/ monocyte cell line (THP-1, catalog \# TIB-202, American Type Culture Collection, Manassas, Va., USA) were cultured according to suppliers' recommendations. Aortic SMCs were stimulated for $18 \mathrm{~h}$ using $50 \mathrm{ng} / \mathrm{ml}$ IFN- $\gamma$ (PeproTech Inc., Rocky Hill, N.J., USA). The monocyte/macrophage cell line was stimulated for $18 \mathrm{~h}$ using $100 \mathrm{ng} / \mathrm{ml}$ LPS (serotype 055:B5, Sigma-Aldrich), and $20 \mathrm{ng} / \mathrm{ml}$ IFN- $\gamma$ [9]. Cells were lysed in RIPA buffer which included protease inhibitors (sc-24948, Santa Cruz Biotechnology, Inc., Santa Cruz, Calif., USA). This stimulation was considered relevant to AAA, since mice lacking IFN- $\gamma$ are resistant to AAA formation in the $\mathrm{CaCl}_{2}$ model [10] and IFN- $\gamma$-producing T cells are present in the blood and aortic wall of most AAA patients [11]. Cell lysates were subjected to SDS-PAGE and immunoblotted as described above.

Immunohistochemical Staining of Aortic Tissue Samples Immunohistochemical staining was carried out using formalin-fixed paraffin-embedded aortic tissue as described previously [12]. The slides were incubated with a primary antibody (online suppl. table S3) on an automatic immunostainer (Autostainer, Dako, Carpinteria, Calif., USA). A secondary antibody with peroxidase labelled polymer conjugated to either goat anti-mouse or goat anti-rabbit immunoglobulins (Dako, Glostrup, Denmark) was used and the signal was detected with substrate chromogen solution (Dako, Glostrup, Denmark). Antibodies for each protein were first tested on tissue known to contain the protein of interest as positive controls. Nonspecific IgG antibody in lieu of primary antibody served as a negative control. For evaluation of the stained slides microscope Nikon OptiPHOT-2 (Japan) and Nikon Digital Camera DXm1200F (Japan) were used.

Pathobiology of Human Abdominal Aortic Aneurysms

\section{Results}

Design of 'AAA-chip' for Validation of Microarray Findings

There is only one published microarray-based expression study comparing human AAA tissues to nonaneurysmal infrarenal abdominal aortas from age- and sexmatched controls [4]. To provide additional evidence for selecting novel, differentially expressed genes for further studies, we carried out a new microarray-based expression analysis and identified 57 genes which were differentially expressed in both studies. KEGG pathway information [13] was available for only 27 of the 57 genes, whereas all except one gene (C13orf18) had GO [14] information. Using information from both of these databases $16(28 \%)$ of the 57 differentially expressed genes have functions in the 'inflammatory response' or the ' $i m$ mune system', another $16(28 \%)$ play a role in 'development and differentiation', 13 (23\%) have functions in 'cell adhesion', and 9 (16\%) are involved in 'calcium signaling' (table 1). Many genes were classified into multiple functional categories.

We then designed a custom 'AAA-chip' with assays for 43 of the 57 differentially expressed genes identified in our two independent microarray studies. Assays for two housekeeping genes were also included on the 'AAA-chip' (online suppl. table S2). The 43 genes selected for further study represented a wide range of biological functional categories with emphasis on genes not previously implicated in AAA pathobiology (table 1). On the 'AAA-chip' all 43 genes and controls can be assayed simultaneously 
Table 2. 'AAA-chip' results for 43 genes selected from a microarray study

\begin{tabular}{|c|c|c|c|c|}
\hline \multirow{2}{*}{$\begin{array}{l}\text { Gene } \\
\text { symbol }\end{array}$} & \multirow{2}{*}{$\begin{array}{l}\text { Gene } \\
\text { ID }\end{array}$} & \multirow{2}{*}{$\begin{array}{l}\text { Microarray } \\
\text { FDR [4] }\end{array}$} & \multicolumn{2}{|l|}{ AAA-chip } \\
\hline & & & fold change & $\mathrm{p}$ value \\
\hline$A D C Y 7$ & 113 & $7.51 \mathrm{e}-4$ & 5.7 & 0.00032 \\
\hline$A R L 4 C$ & 10123 & $2.01 \mathrm{e}-5$ & 6.4 & 0.0007 \\
\hline$B L N K$ & 17060 & $6.46 e-3$ & 7.1 & 0.00002 \\
\hline CCL4 & 6351 & $2.57 \mathrm{e}-8$ & 18.3 & 0.00032 \\
\hline CCL8 & 6355 & $2.25 \mathrm{e}-2$ & 23.0 & 0.00005 \\
\hline CD4 & 920 & $3.15 e-6$ & 4.3 & 0.00314 \\
\hline CD48 & 109530 & $9.21 \mathrm{e}-4$ & 20.3 & 0.00004 \\
\hline$C D 83$ & 9308 & $2.91 \mathrm{e}-7$ & 10.1 & 0.00063 \\
\hline CSRP2 & 13008 & $1.02 \mathrm{e}-8$ & -2.3 & 0.00316 \\
\hline CXCR4 & 7852 & $4.84 \mathrm{e}-5$ & 6.9 & 0.00032 \\
\hline CYTIP & 9595 & $1.52 \mathrm{e}-4$ & 6.2 & 0.00042 \\
\hline DUSP6 & 1848 & $6.61 \mathrm{e}-3$ & 4.2 & 0.00083 \\
\hline FCGR2B & 2213 & $4.34 \mathrm{e}-3$ & 9.5 & 0.00039 \\
\hline$F O S B$ & 2354 & $9.08 \mathrm{e}-5$ & 34.1 & 0.00014 \\
\hline GATM & 2628 & $8.15 e-4$ & 3.1 & 0.00083 \\
\hline GPR65 & 8477 & $8.43 e-8$ & 6.6 & 0.0007 \\
\hline HSPB2 & 3316 & $2.92 \mathrm{e}-11$ & -3.0 & 0.01568 \\
\hline IL10RA & 3587 & $1.74 \mathrm{e}-7$ & 9.7 & 0.00001 \\
\hline ITGA10 & 8515 & $4.69 \mathrm{e}-3$ & -1.9 & 0.11207 \\
\hline ITGA5 & 3678 & $2.23 \mathrm{e}-2$ & -1.1 & 0.34531 \\
\hline LARP6 & 55323 & $2.13 \mathrm{e}-6$ & 1.0 & 0.72031 \\
\hline$L C P 2$ & 3937 & $2.90 \mathrm{e}-7$ & 6.1 & 0.00042 \\
\hline LDOC1 & 23641 & $5.65 e-9$ & -5.3 & 0.00367 \\
\hline LMOD1 & 25802 & $5.01 \mathrm{e}-9$ & -5.0 & 0.00589 \\
\hline$L Y Z$ & 4069 & $2.44 \mathrm{e}-5$ & 13.9 & 0.00008 \\
\hline$M A R C K S$ & 4082 & $1.29 \mathrm{e}-6$ & 4.1 & 0.00014 \\
\hline MFGE8 & 4240 & $7.21 \mathrm{e}-8$ & -4.6 & 0.00003 \\
\hline$M X 2$ & 4600 & $1.31 \mathrm{e}-6$ & 4.6 & 0.00058 \\
\hline NCF4 & 4689 & $1.77 \mathrm{e}-6$ & 5.7 & 0.00032 \\
\hline NPTX2 & 4885 & $2.17 \mathrm{e}-13$ & -2.1 & 0.32455 \\
\hline NTRK3 & 4916 & $3.55 \mathrm{e}-15$ & -2.7 & 0.01126 \\
\hline PDE8B & 8622 & $1.22 \mathrm{e}-18$ & -7.2 & 0.00987 \\
\hline PLEK & 5341 & $4.46 e-5$ & 7.8 & 0.00011 \\
\hline PRUNE2 & 58497 & $2.78 \mathrm{e}-6$ & -5.1 & 0.00754 \\
\hline PTPRC & 5788 & $4.15 e-5$ & 6.9 & 0.00167 \\
\hline$R A M P 1$ & 10267 & $3.77 e-18$ & -5.9 & 0.00864 \\
\hline RASL12 & 51285 & $1.03 \mathrm{e}-10$ & 1.5 & 0.34073 \\
\hline SAMSN1 & 64092 & $3.02 \mathrm{e}-4$ & 8.7 & 0.00001 \\
\hline SMARCD3 & 6604 & $6.01 \mathrm{e}-7$ & -2.0 & 0.04533 \\
\hline SMTN & 6525 & $3.08 \mathrm{e}-6$ & -2.8 & 0.00754 \\
\hline TMOD1 & 7111 & $2.33 \mathrm{e}-11$ & -4.2 & 0.00026 \\
\hline TPM2 & 7169 & $1.13 \mathrm{e}-17$ & -4.5 & 0.001 \\
\hline ZBTB16 & 7704 & $4.38 \mathrm{e}-13$ & -2.8 & 0.00657 \\
\hline
\end{tabular}

A custom PCR Array called 'AAA-chip' was designed with 43 genes selected from the microarray study (see online suppl. table S2 for the design of the 'AAA-chip') and used to analyze RNA isolated from a new set of 15 human AAA samples and 15 control abdominal aorta samples (for details on the donors, see online suppl. table $\mathrm{S} 1$ ). The p values were calculated using the Wilcoxon rank-sum test.

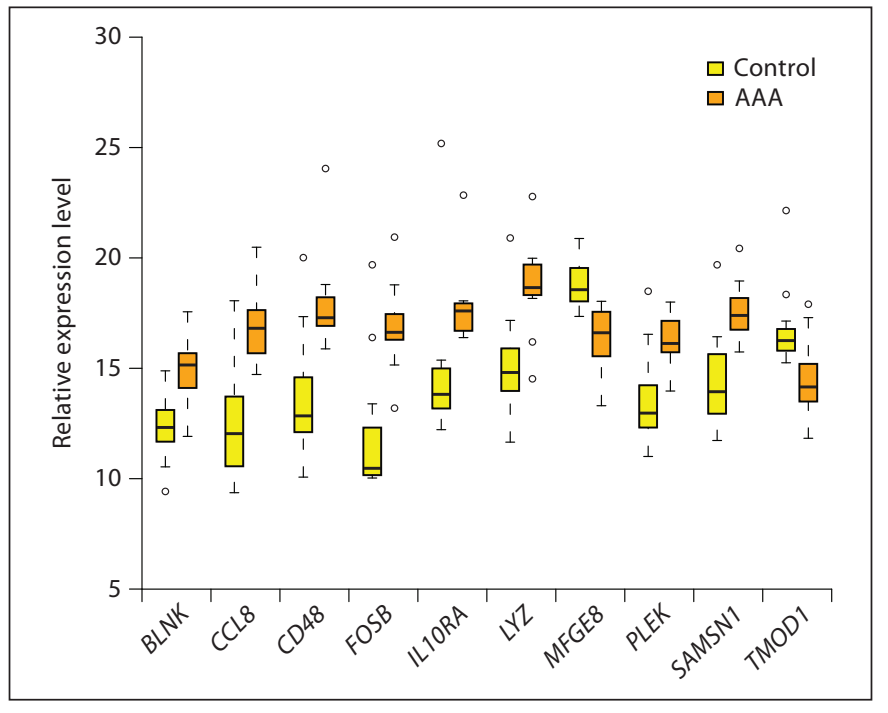

Fig. 1. The 10 most differentially expressed genes based on a custom PCR Array, the 'AAA-chip'. Box and whisker plots of mRNA levels for 10 genes analyzed on 15 AAA cases and 15 control abdominal aorta samples are shown. RNA expression levels for each gene under study are indicated on the ordinate-axis relative to expression of two housekeeping genes (GAPDH and RPL13A). See table 2 for $p$ values for statistical tests comparing the AAA and control groups.

for two RNA samples using real-time quantitative (Q)RT-PCR technique. We tested an independent set of RNA samples isolated from 15 AAA tissues and 15 nonaneurysmal infrarenal abdominal aortic tissues (online suppl. table S1). The mRNA levels were significantly different between AAA and control samples in 38/43 (88\%) genes tested with the custom 'AAA-chip' (fig. 1; table 2), and the direction of the change was the same found in both microarray studies. There was, however, no direct correlation of the level of significance between the microarray and 'AAA-chip' results (table 2). Two of the most surprising results were with NPTX2 and RASL12, which had highly significant results (FDR of $2.17 \mathrm{e}-13$ and $1.03 \mathrm{e}-10$, respectively) in our microarray analysis [4], but showed no significant differences when assayed in the 'AAA-chip' with a new set of samples.

Network analysis using IPA tools was carried out for the 38 differentially expressed genes (fig. 2; online suppl. fig. S1). Ten (CXCR4, CD4, PTPRC, CD83, CCL4, CCL8, $F O S B, B L N K, L C P 2$ and FCGR2B) of the 38 genes had a very large number $(\geq 10)$ of direct interactions with other molecules (online suppl. fig. S1). All of these 10 genes showed increased mRNA expression in AAA compared to controls. With the exception of FOSB all play a role in 


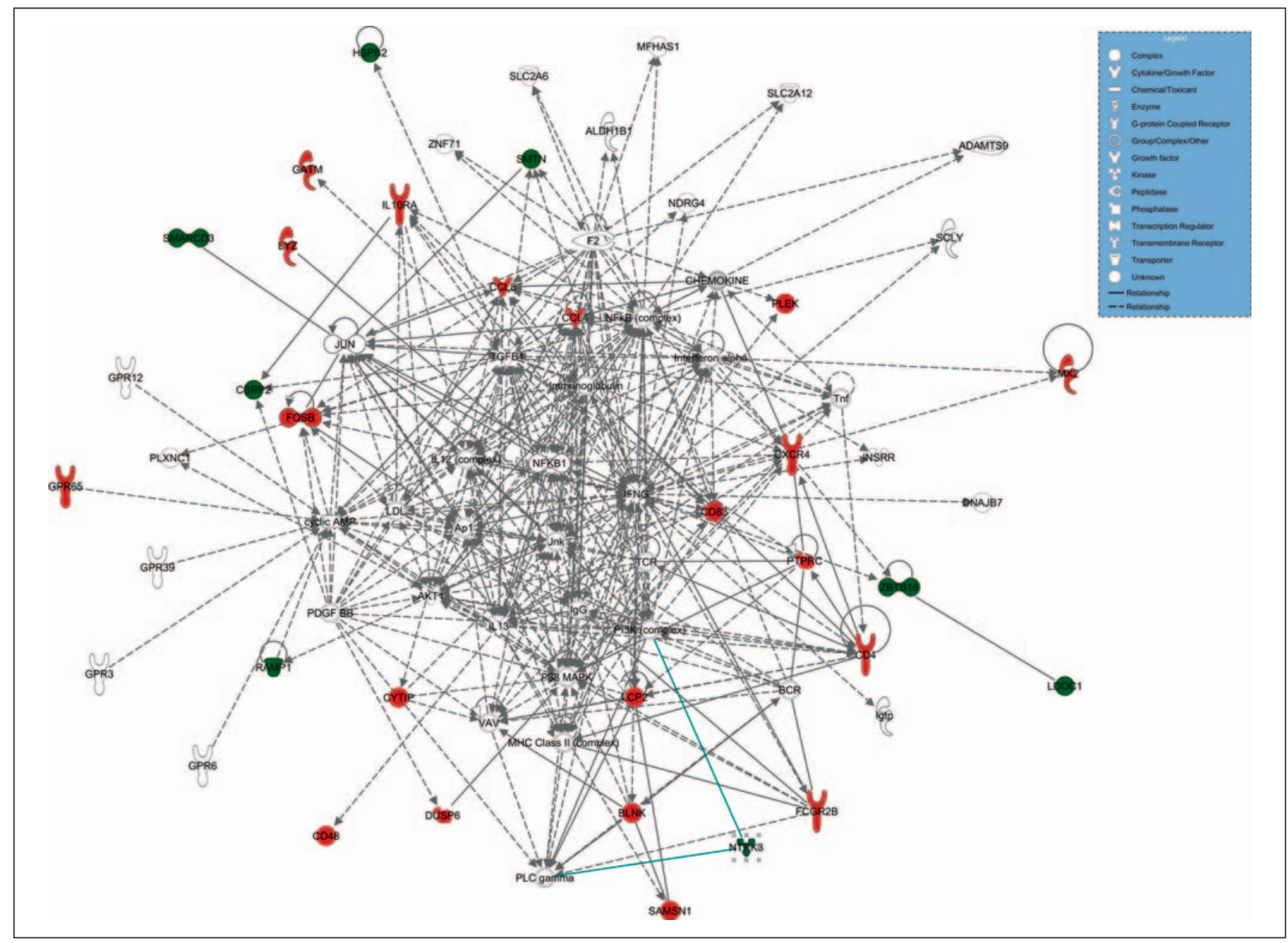

Fig. 2. A subset of a network of the 38 differentially expressed genes in AAA. The complete network figure is available in the supplementary material online, fig. S1. The upregulated and downregulated genes are shown in red and green, respectively. Molecules are represented as nodes, and the biological relationship between two nodes is represented as a line. Nodes are displayed using various shapes that represent the functional class of the gene product. Solid lines represent direct interactions and dashed lines indirect interactions.

the inflammatory response. Only one interaction was found for another set of 10 genes: $P D E 8 B, L M O D 1$, GPR65, SMARCD3, MFGE8, HSPB2, GATM, CD48, LCOC1, and $L Y Z$ (online suppl. fig. S1).

\section{Protein Levels of Differentially Expressed Genes Vary} between AAA and Controls

Protein analysis using Western blotting and specific antibodies revealed that the amounts of PTPRC (2.7fold), CD4 (2.6-fold), and GATM (4.3-fold) were increased (fig. 3). These results are in agreement with the 'AAA-chip' results where 6.9-, 4.3-, and 3.1-fold increases for PTPRC, CD4, and GATM mRNAs, respectively, were found (table 2). Protein lysates prepared from cultured human macrophages produced intense bands of expected sizes for all three proteins, whereas none of them were detectable in the aortic SMCs (fig. 3).

\section{Immunohistochemical Localization of Differentially Expressed Proteins}

Immunohistochemical staining with antibodies against 10 different proteins representing different biological pathways (table 1) was evaluated in AAA and infrarenal abdominal aortic control tissue: PTPRC (CD45), CD4, CXCR4, BLNK, PLEK, LYZ, FOSB, DUSP6, ITGA5 and GATM. 


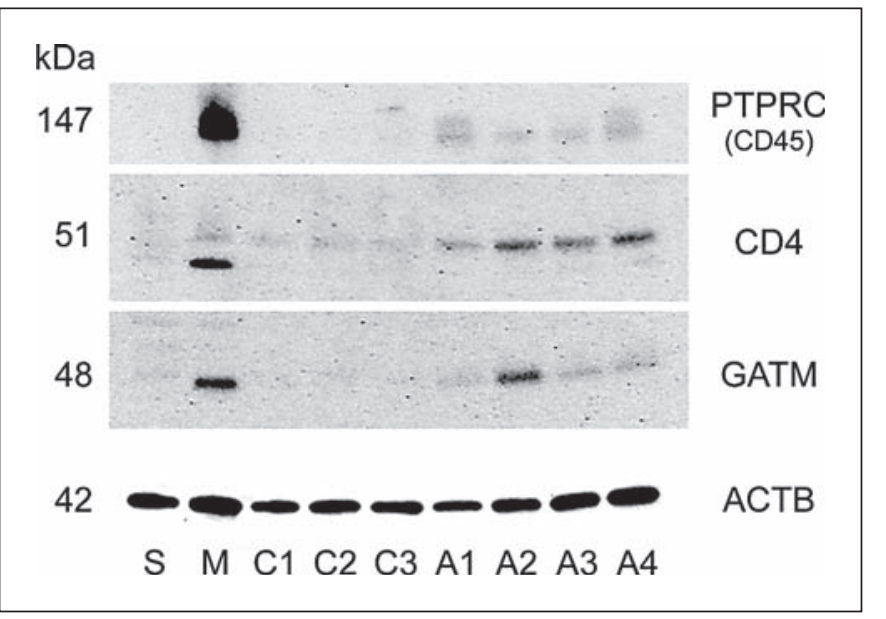

Fig. 3. Western blots for PTPRC, CD4, GATM, and ACTB. Protein lysates of cultured human smooth muscle cells (S) and monocytes $(\mathrm{M})$ as well as of abdominal aortic tissues from controls (C1, $\mathrm{C} 2, \mathrm{C} 3$ ) and AAA patients (A1, A2, A3, A4) were used. The molecular weights $(\mathrm{kDa})$ of the observed bands are indicated on the left and the protein names on the right. ACTB was used to standardize for the amount of protein on the gel.

Both antibodies against PTPRC (CD45) demonstrated staining on lymphocytes in the AAA as well as control aortic tissue. Multiple infiltrating lymphocytes in adventitia, media, and endothelium of AAA tissue were strongly positive for CD45 in the cytoplasm and membrane (fig. 4). In control aortic tissue only few lymphocytes were present (fig. 4). One control aortic tissue sample with a high grade of atherosclerosis was infiltrated by CD45positive lymphocytes similar to the AAA tissue (not shown). Myocytes, ECM, neovessels, peripheral nerve, and thrombus did not stain with the CD45 antibodies.

CD4 antibody showed strong staining in lymphocytes which were more abundant in the adventitia and media of AAA tissue than in the control (fig. 4). Myocytes, ECM, neovessels, peripheral nerve, and thrombus did not stain with CD4 antibody. The results seen here in AAA were in agreement with a previous study [15].

In agreement with a previous study [16], CXCR4 staining appeared to be on lymphocytes in the adventitia and media of the AAA tissues. As a known T cell marker, it had a similar distribution to CD4 (fig. 4). BLNK also showed a strong staining in lymphocytes in the adventitia and in some inflammatory cells in the media of AAA. In addition, VSMCs in the media of both AAA and control tissues demonstrated a faint nuclear reactivity against the BLNK antibody (fig. 4). PLEK and DUSP6 antibodies showed strong staining in lymphocytes in the adventitia and media of AAA with no reactivity in control aorta (fig. 4). LYZ antibody gave a strong staining in inflammatory cells in adventitia and media of AAA; some of the inflammatory cells were most likely neutrophils based on the nucleus (fig. 4). The antibody against FOSB showed a staining on lymphocytes in the adventitia and media of AAA samples. In addition, endothelial cells in the vasa vasorum stained positive for FOSB in both AAA and control tissues (fig. 4).

Based on the immunostaining, ITGA5 was expressed in myofibroblasts in the control aorta, but not in the AAA tissues (fig. 4), a finding which is consistent with previously published results [17].

GATM antibody showed positive staining only in few inflammatory cells in the adventitia (mostly in the nearby lymphatic tissue) of AAA and more in the intima layer (fig. 4). Control aortic tissue showed single GATMpositive cells in the adventitia layer and rarely in the intima (fig. 4). Peripheral nerve tissue and thrombus were negative (not shown).

\section{Discussion}

In the current study, we followed-up our previously published microarray-based expression profiling [4] and validated novel genes involved in AAA pathogenesis. Additionally, we used Western blotting and immunohistochemical staining to study the corresponding proteins in the aortic wall.

Multiple genes were discovered which had not been previously implicated in AAA. Out of the 43 genes selected for Q-RT-PCR analysis performed using a custom 'AAA-chip', all but 5 were confirmed as being significantly different in AAA. By choosing an independent casecontrol set for the Q-RT-PCR we provided not only technical but also biological replication of the microarray expression results. Reasons why we could not confirm the expression difference for 5 of the 43 genes are multiple and can be due to heterogeneity of the AAA tissues samples, including samples from AAAs of different sizes and grades of inflammation, adherent material of thrombus and presence of atherosclerosis.

We will discuss here the potential role of several novel genes in AAA pathobiology. FOSB demonstrated the greatest fold change (34-fold difference) between aneurysmal and non-aneurysmal tissues and was highly significant $(\mathrm{p}=0.00014)$. In agreement with the mRNA results, staining for FOSB protein was more intense in AAA tissues than controls (fig. 4). The GO database character- 
Fig. 4. Immunohistochemical staining with antibodies against 10 different proteins representing different biological pathways. Each row shows representative immunohistological images for one of the antibodies on AAA tissue and control abdominal aortic tissue. Most antibodies demonstrated staining on inflammatory cells in the AAA tissue. Scale bar $=50 \mu \mathrm{m}$.

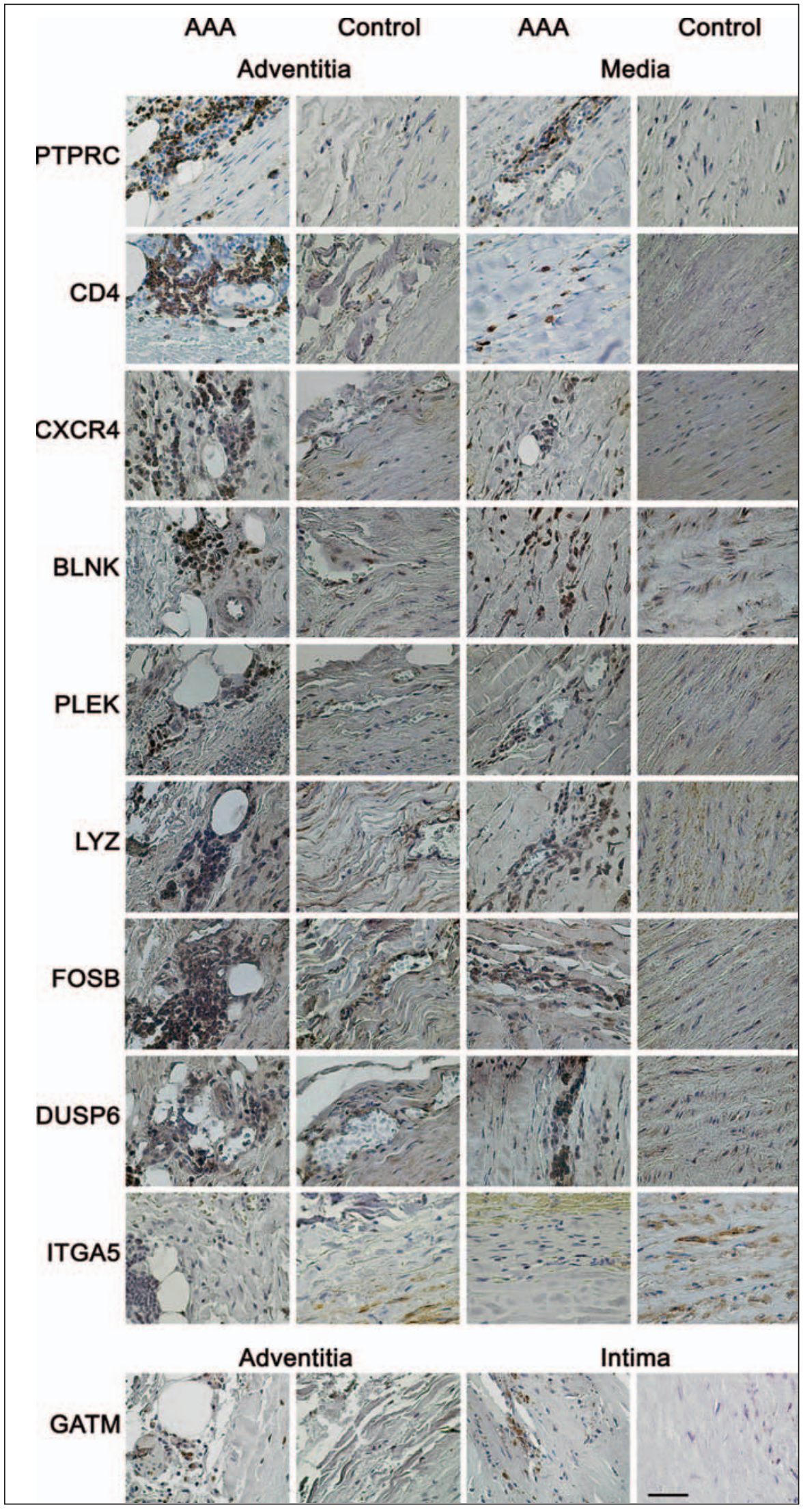

Pathobiology 2013;80:1-10 
izes FOSB, or FBJ murine osteosarcoma viral oncogene homolog B, with 'behavioral and developmental' biological processes [14]. Proteins of the FOS family dimerize with members of the JUN family enhancing their ability to bind to DNA and act as transcription factors [18]. Transcription factors associated with FOS family proteins, such as AP1, are involved in cell differentiation, proliferation, and apoptosis [19]. It is possible that AP1 plays a role in VSMC apoptosis which is characteristic of AAA or regulate the transcription of other genes associated with the disease mechanism.

$L Y Z$ was also among the most significant differentially expressed genes $(\mathrm{p}=0.00009)$ with a fold change of 14 . $L Y Z$ encodes the human enzyme, lysozyme, which is secreted by phagocytic cells as a defense mechanism of innate immunity. Lysozyme breaks down peptidoglycan in invading bacterial cell walls [20]. The observed up-regulation of $L Y Z$ in AAA on both mRNA and protein level is most interesting because microorganisms have been suggested as triggers in the pathogenesis of the disease [21]. One possible explanation for the increased expression of $L Y Z$ could be that as an aneurysm forms, pathogens traveling through the bloodstream may accumulate in the adherent thrombus of the dilated aortic wall triggering a local infection [22]. In response, the surrounding tissues recruit cells which would excrete lysozyme to fight off the bacterial infection. Another possibility is that phagocytic cells are recruited to the site of the aneurysm once apoptosis of the VSMCs starts, and the immune system is tricked into thinking a bacterial infection is harming the SMCs generating an autoimmune response to fight off a hypothetical invasion.

MFGE8 was found to be downregulated in AAA tissues with a fold change of -4.6 and a highly significant $p$ value ( $\mathrm{p}=0.00003$ ). $M F G E 8$, or milk fat globule epidermal growth factor 8 , encodes the protein lactadherin. Lactadherin is secreted by phagocytic cells and binds proteins on the surfaces of apoptotic cells to integrins, marking them for removal [23]. Since MFGE8 expression is decreased in AAA tissue, it suggests that the function of the lactadherin may be compromised and apoptotic cells may not be properly marked for removal. Studies have shown that failure to remove apoptotic cells can result in inflammation and autoimmune response [24].

Five of the genes with significant differences in the expression (table 2) between AAA and controls were also found to be significantly different in intracranial aneurysm: TMOD1, LYZ [25], NTRK3 [26], PRUNE2 and SMTN $[25,26]$. SMTN has an important function in the development, structure and contraction of the muscle
[27]. In cell culture experiments SMTN was detected in the media of adult VSMCs [28]. Smtn-deficient mice were prone to hypertension and cardiac hypertrophy due to reduced arterial contractility [29]. NTRK3 is a tyrosine kinase receptor and has functions in development and differentiation of multicellular organisms. Ntrk3-deficient mice have multiple cardiac malformations and a reduced number of stem cells [30]. A possible pathobiological mechanism in aneurysms could be that decreased amount of NTRK3 interferes with the differentiation process of VSMCs.

$A D C Y 7$ whose mRNA was significantly increased in AAA tissue, encodes a membrane-bound adenylate cyclase that catalyses the formation of cyclic AMP from ATP [31]. It is the major form of ADCY in human platelets [32]. It also plays a role in chemokine and calcium signaling pathways [31]. In VSMCs, it activates muscle contraction (KEGG pathway map04270) [33].

Genes involved in development and differentiation include SMTN and NTRK3 (discussed above), as well as GATM, CSRP2, HSPB2 and PTPRC. GATM functions in many metabolic (threonine, serine, arginine, proline) pathways, in creatinine biosynthesis, embryonic development, and tissue regeneration. It is a mitochondrial enzyme that belongs to the amidinotransferase family and forms the precursor of creatinine (by catalyzing the transfer of a guanido group from arginine to glycine, forming guanidinoacetic acid, the immediate precursor of creatine) [34]. GATM levels were significantly increased in patients with heart failure; interestingly this was reversible after treatment of the heart failure [35]. GATM mRNA expression was significantly increased in AAA (confirmed on protein level in Western blotting and immunostaining; fig. 3,4 ) which could contribute to the higher creatinine serum levels seen in AAA patients [36].

CSRP2, which had decreased expression in AAA, is another gene which functions in myoblast differentiation and muscle development; it is expressed in the aorta and was down regulated in arterial wall injury in a previous mouse study [37].

HSPB2, which was reduced in AAA, is a stress protein and is highly expressed in skeletal muscle. A role in cardioprotection could be shown ex vivo, but in vivo or in humans the biological function is poorly defined [38].

PTPRC (also known as CD45) is a membrane protein that had increased mRNA and protein expression in aortic tissue in the current study, whereas it was decreased in peripheral blood of AAA patients in a previous microarray study [6]. According to GO [14] it has multiple functions but amongst others plays a role in the regulation of 
the cell cycle, in focal adhesion and releasing of sequestered calcium ion into the cytosol. The extracellular domains of the family of PTPRs resemble those of cell adhesion molecules [39]. The subtype PTPRG has been shown to interact with contactin 3 [39], which was found to harbor polymorphisms associated with AAA in a genomewide association study [40]. PTPRC protein levels were increased in AAA based on Western blotting and immunohistochemical analysis (fig. 3, 4). A strong positive immunostaining was seen in the inflammatory cells infiltrating the AAA wall, which were not present in control aortic tissue (fig. 4). The results were consistent with a previously published study on CD45 protein in ruptured AAA [41]. Some of the control aortas also showed intense staining for PTPRC suggesting that elevated PTPRC expression is an unspecific marker of inflammatory processes of the aortic wall.

CD4 is a membrane protein with roles in immune function, cell adhesion and regulation of calcium-mediated signaling. CD4 mRNA was significantly increased in AAA tissue, confirmed by protein analysis, which agrees with previous studies (fig. 3, 4) [15]. A crucial role for CD4 in the development of AAA as part of an autoimmune injury has been shown in an animal study [10].

Two additional genes without well-known biological functions were RAMP1 and NCF4. RAMP1, which had reduced mRNA levels in AAA, is a member of a family of calcitonin receptor modifying proteins and is thought to have a crucial role in the regulation of blood pressure by vascular relaxation. Ramp1-deficient mice exhibited high blood pressure with no changes in heart rate [42]. NCF4, which was increased in AAA, is a cytosolic regulatory component of the superoxide-producing phagocyte NADPH-oxidase (NOX complex), which is a multi-enzyme complex important for host defense. An NCF4 gene variant was associated with rheumatoid arthritis in male patients [43]; thus, this gene might play a role in the autoimmune processes of AAA development.

\section{Limitations}

A severe limitation of all human studies on AAA is the fact that tissue specimens can be obtained only from the end-stage disease, when the AAA has grown large enough to warrant an operative repair. In most cases the architecture of the aortic wall has changed considerably. Phenotypic heterogeneity of the collected AAA samples is also a potential limitation, since the aortic wall samples contain a mixture of different cell types, some of which (e.g. inflammatory cells) are not normally present in the aortic wall. Other diseases, such as local atherosclerotic changes in older age groups, also complicate the interpretation of the results.

In conclusion, new genes, not previously implicated in AAA pathogenesis, were discovered by using an unbiased genomewide analysis. The confirmation of $38 / 43$ genes tested by custom 'AAA-chip' increases the level of confidence that the identified genes are differentially expressed and contribute to AAA pathogenesis. The genes identified here provide new pathways for future studies to elucidate the details of AAA pathogenesis.

\section{Acknowledgements}

We acknowledge use of human aortic tissues provided by the National Disease Research Interchange (NDRI), with support from NIH grant 5 U42 RR006042-20. This work was supported by the National Heart, Lung, and Blood Institute (HL064310 to H.K.), NIH, and the American Heart Association Great Rivers Affiliate (to D.J.C.), as well as by Geisinger Clinic. I.H. is a recipient of a Fellowship from Deutsche Forschungsgemeinschaft ( $\mathrm{Hi}$ 1479/2-1) and from the Technical University of Dresden ('Frauenhabilitationsstipendium der Medizinischen Fakultät Dresden'), Germany. J.H.L. is a recipient of a Predoctoral Fellowship from the National Institute on Aging, NIH (AG030900).

\section{References}

-1 Sakalihasan N, Limet R, Defawe OD: Abdominal aortic aneurysm. Lancet 2005;365: 1577-1589.

2 Heron M: National Vital Statistics Reports: from the centers for disease control and prevention, national center for health statistics. National Vital Statistics System 2011;59:195.

-3 Boddy AM, Lenk GM, Lillvis JH, Nischan J, Kyo Y, Kuivaniemi H: Basic research studies to understand aneurysm disease. Drug News Perspect 2008;21:142-148.

4 Lenk GM, Tromp G, Weinsheimer S, Gatalica Z, Berguer R, Kuivaniemi H: Whole genome expression profiling reveals a significant role for immune function in human abdominal aortic aneurysms. BMC Genomics 2007;8:237.

5 Choke E, Cockerill GW, Laing K, Dawson J, Wilson WR, Loftus IM, Thompson MM:
Whole genome-expression profiling reveals a role for immune and inflammatory response in abdominal aortic aneurysm rupture. Eur J Vasc Endovasc Surg 2009;37:305-310.

6 Giusti B, Rossi L, Lapini I, Magi A, Pratesi G, Lavitrano M, Biasi GM, Pulli R, Pratesi C, Abbate R: Gene expression profiling of peripheral blood in patients with abdominal aortic aneurysm. Eur J Vasc Endovasc Surg 2009;38:104-112. 
7 Gentleman RC, Carey VJ, Bates DM, Bolstad B, Dettling M, Dudoit S, Ellis B, Gautier L, Ge Y, Gentry J, Hornik K, Hothorn T, Huber $\mathrm{W}$, Iacus $\mathrm{S}$, Irizarry $\mathrm{R}$, Leisch $\mathrm{F}, \mathrm{Li} \mathrm{C}$, Maechler M, Rossini AJ, Sawitzki G, Smith C, Smyth G, Tierney L, Yang JY, Zhang J: Bioconductor: open software development for computational biology and bioinformatics. Genome Biol 2004;5:R80.

8 R Development Core Team: R: A Language and Environment for Statistical Computing [Computer Program]. Vienna, R Foundation for Statistical Computing, 2009.

-9 Martinez FO, Gordon S, Locati M, Mantovani A: Transcriptional profiling of the human monocyte-to-macrophage differentiation and polarization: new molecules and patterns of gene expression. J Immunol 2006; 177:7303-7311.

10 Xiong W, Zhao Y, Prall A, Greiner TC, Baxter BT: Key roles of CD4+ T cells and IFNgamma in the development of abdominal aortic aneurysms in a murine model. J Immunol 2004;172:2607-2612.

-11 Duftner C, Seiler R, Klein-Weigel P, Gobel H, Goldberger C, Ihling C, Fraedrich G, Schirmer M: High prevalence of circulating CD4+CD28- T-cells in patients with small abdominal aortic aneurysms. Arterioscler Thromb Vasc Biol 2005;25:1347-1352.

-12 Tromp G, Gatalica Z, Skunca M, Berguer R, Siegel T, Kline RA, Kuivaniemi H: Elevated expression of matrix metalloproteinase-13 in abdominal aortic aneurysms. Ann Vasc Surg 2004;18:414-420.

13 Kanehisa M, Goto S: Kegg: Kyoto encyclopedia of genes and genomes. Nucleic Acids Res 2000;28:27-30.

14 Barrell D, Dimmer E, Huntley RP, Binns D, O'Donovan C, Apweiler R: The GOA database in 2009 - an integrated gene ontology annotation resource. Nucleic Acids Res 2009;37:D396-D403.

15 Abdul-Hussien H, Hanemaaijer R, Kleemann $\mathrm{R}$, Verhaaren BF, van Bockel JH, Lindeman $\mathrm{JH}$ : The pathophysiology of abdominal aortic aneurysm growth: Corresponding and discordant inflammatory and proteolytic processes in abdominal aortic and popliteal artery aneurysms. J Vasc Surg 2010;51:1479-1487.

- 16 Ocana E, Perez-Requena J, Bohorquez JC, Brieva JA, Rodriguez C: Chemokine receptor expression on infiltrating lymphocytes from abdominal aortic aneurysms: Role of CXCR4-CXCL12 in lymphoid recruitment. Atherosclerosis 2008;200:264-270.

$\checkmark 17$ Cheuk BL, Cheng SW: Differential expression of integrin alpha5betal in human abdominal aortic aneurysm and healthy aortic tissues and its significance in pathogenesis. J Surg Res 2004;118:176-182.

-18 Baumann S, Hess J, Eichhorst ST, Krueger A, Angel P, Krammer PH, Kirchhoff S: An unexpected role for FOSB in activation-induced cell death of T cells. Oncogene 2003; 22:1333-1339.

-19 Ameyar M, Wisniewska M, Weitzman JB: A role for AP-1 in apoptosis: the case for and against. Biochimie 2003;85:747-752.
20 Levy O, Martin S, Eichenwald E, Ganz T, Valore E, Carroll SF, Lee K, Goldmann D, Thorne GM: Impaired innate immunity in the newborn: Newborn neutrophils are deficient in bactericidal/permeability-increasing protein. Pediatrics 1999;104:1327-1333.

21 Hinterseher I, Gäbel G, Corvinus F, Lück C, Saeger HD, Bergert H, Tromp G, Kuivaniemi $\mathrm{H}$ : Presence of borrelia burgdorferi sensu lato antibodies in the serum of patients with abdominal aortic aneurysms. Eur J Clin Microbiol Infect Dis 2012;31:781-789.

-22 Marques da Silva R, Lingaas PS, Geiran O, Tronstad L, Olsen I: Multiple bacteria in aortic aneurysms. J Vasc Surg 2003;38:1384-1389.

23 Dasgupta SK, Guchhait P, Thiagarajan P: Lactadherin binding and phosphatidylserine expression on cell surface-comparison with annexin A5. Transl Res 2006;148:19-25.

24 Hanayama R, Tanaka M, Miyasaka K, Aozasa K, Koike M, Uchiyama Y, Nagata S: Autoimmune disease and impaired uptake of apoptotic cells in MFG-E8-deficient mice. Science 2004;304:1147-1150.

25 Shi C, Awad IA, Jafari N, Lin S, Du P, Hage ZA, Shenkar R, Getch CC, Bredel M, Batjer $\mathrm{HH}$, Bendok BR: Genomics of human intracranial aneurysm wall. Stroke 2009; 40: 1252-1261.

-26 Pera J, Korostynski M, Krzyszkowski T, Czopek J, Slowik A, Dziedzic T, Piechota M, Stachura K, Moskala M, Przewlocki R, Szczudlik A: Gene expression profiles in human ruptured and unruptured intracranial aneurysms. What is the role of inflammation? Stroke 2010;41:224-231.

27 Krämer J, Quensel C, Meding J, Cardoso $\mathrm{MC}$, Leonhardt $\mathrm{H}$ : Identification and characterization of novel smoothelin isoforms in vascular smooth muscle. J Vasc Res 2001;38: $120-132$.

28 Johansson B, Eriksson A, Ramaekers F, Thornell L: Smoothelin in adult and developing human arteries and myocardium. Histochem Cell Biol 1999;112:291-299.

29 Rensen SS, Niessen PM, van Deursen JM, Janssen BJ, Heijman E, Hermeling E, Meens M, Lie N, Gijbels MJ, Strijkers GJ, Doevendans PA, Hofker MH, De Mey JG, van Eys GJ: Smoothelin-b deficiency results in reduced arterial contractility, hypertension, and cardiac hypertrophy in mice. Circulation 2008; 118:828-836.

30 Youn YH, Feng J, Tessarollo L, Ito K, SieberBlum M: Neural crest stem cell and cardiac endothelium defects in the TRKC null mouse. Mol Cell Neurosci 2003;24:160-170.

31 Beeler JA, Yan SZ, Bykov S, Murza A, Asher $\mathrm{S}$, Tang WJ: A soluble Clb protein and its regulation of soluble type 7 adenylyl cyclase. Biochemistry 2004;43:15463-15471.

32 Hellevuo K, Berry R, Sikela JM, Tabakoff B: Localization of the gene for a novel human adenylyl cyclase (ADCY7) to chromosome 16. Hum Genet 1995;95:197-200.

- 33 Akata T: Cellular and molecular mechanisms regulating vascular tone. 2. Regulatory mechanisms modulating $\mathrm{Ca}^{2+}$ mobilization and/or myofilament $\mathrm{Ca}^{2+}$ sensitivity in vascular smooth muscle cells. J Anesth 2007;21:232-242.

34 Humm A, Fritsche E, Steinbacher S, Huber R: Crystal structure and mechanism of human L-arginine: glycine amidinotransferase. A mitochondrial enzyme involved in creatine biosynthesis. EMBO J 1997;16:3373-3385.

35 Cullen ME, Yuen AH, Felkin LE, Smolenski RT, Hall JL, Grindle S, Miller LW, Birks EJ, Yacoub MH, Barton PJ: Myocardial expression of the arginine: glycine amidinotransferase gene is elevated in heart failure and normalized after recovery. Potential implications for local creatine synthesis. Circulation 2006;114:I16-I20.

36 Nakamura S, Ishibashi-Ueda H, Suzuki C, Nakata H, Yoshihara F, Nakahama H, Kawano Y: Renal artery stenosis and renal parenchymal damage in patients with abdominal aortic aneurysm proven by autopsy. Kidney Blood Press Res 2009;32:11-16.

37 Jain MK, Fujita KP, Hsieh CM, Endege WO, Sibinga NE, Yet SF, Kashiki S, Lee WS, Perrella MA, Haber E, Lee ME: Molecular cloning and characterization of SMLIM, a developmentally regulated LIM protein preferentially expressed in aortic smooth muscle cells. J Biol Chem 1996;271:10194-10199.

- 38 Benjamin IJ, Guo Y, Srinivasan S, Boudina S, Taylor RP, Rajasekaran NS, Gottlieb R, Wawrousek EF, Abel ED, Bolli R: CRYAB and HSPB2 deficiency alters cardiac metabolism and paradoxically confers protection against myocardial ischemia in aging mice. Am J Physiol Heart Circ Physiol 2007; 293:H3201-H3209.

39 Bouyain S, Watkins DJ: The protein tyrosine phosphatases PTPRZ and PTPRG bind to distinct members of the contactin family of neural recognition molecules. Proc Natl Acad Sci USA 2010;107:2443-2448.

40 Elmore JR, Obmann MA, Kuivaniemi H, Tromp G, Gerhard GS, Franklin DP, Boddy AM, Carey DJ: Identification of a genetic variant associated with abdominal aortic aneurysms on chromosome $3 \mathrm{p} 12.3$ by genome wide association. J Vasc Surg 2009;49:1525-1531.

41 Treska V, Kocova J, Boudova L, Neprasova P, Topolcan O, Pecen L, Tonar Z: Inflammation in the wall of abdominal aortic aneurysm and its role in the symptomatology of aneurysm. Cytokines Cell Mol Ther 2002;7:91-97.

\42 Tsujikawa K, Yayama K, Hayashi T, Matsushita H, Yamaguchi T, Shigeno T, Ogitani Y, Hirayama M, Kato T, Fukada S, Takatori S, Kawasaki H, Okamoto H, Ikawa M, Okabe M, Yamamoto H: Hypertension and dysregulated proinflammatory cytokine production in receptor activity-modifying protein 1-deficient mice. Proc Natl Acad Sci USA 2007;104:16702-16707.

43 Olsson LM, Lindqvist AK, Kallberg H, Padyukov L, Burkhardt H, Alfredsson L, Klareskog L, Holmdahl R: A case-control study of rheumatoid arthritis identifies an associated single nucleotide polymorphism in the NCF4 gene, supporting a role for the NADPH-oxidase complex in autoimmunity. Arthritis Res Ther 2007;9:R98. 